\title{
AHLU KITAB MENURUT SAYYID QUTHB DALAM TAFSIR FI ZILAL Al-QUR'AN
}

\author{
Heru Mustakim \\ Sekolah Menengah Pertama Islam Terpadu Ar-Risalah Surakarta \\ E-Mail: heru_mustakim@yahoo.co.id
}

\begin{abstract}
The destination that Allah created human being is to whorship to Allah as an instruction and explanation about whorship. Then Allah sent down his Qur'an and delivered his Prophet as conveyars of the role of the Allah and the lost Kitab that has been sent down to Muhammad SAW as the instruction and figure for the moslems people untill the end of time. The meeting among Islam and Christian and Jew has been running since the birth of Islam in Jazeera. The first century of Masehi, in tht meeting the holy Qur'an is a holy book for moslems took its possision as the corrector for the holy books before. Especially the holy book that has been brought by christians, it's called Al Kitab. The problems about Ahlu Kitab (Jew and Christian) are very important to be explained, because these problems impact to our aqidah, whorship, relationship many kinds of aspect of life for moslems, beside that the meaning of Ahlu Kitab who is Ahlu Kitab is still cuarreled by ulama, especially still cuarreted by ulama, that this kitab is only for Jew and Christian or there is still group out of them that include in them. Sayyid Qutb is controversi Mufassir among moslems and far ikhwaanul Muslimin. Sayyid Qutb is a figure that was loved by Moslems and as an inspirator for them but in another way the thought of Sayyid Qutb was given comment by ulama' because of trouble understanding the verse of Holy Qur'an, and some deviation in his aqidah, especially about takfir to the people that have different understanding. After his death Sayyid Qutb's ideology doesn't lose away and decrease, in other hand it develope more not only in Egypt but spread to all of countries in the world, finally fondamentalist movement appeared. So that the writter wanted to analyze about the Ahlu Kitab depended on Sayyid Qutb's book, called Tafsir fie dhilail Qur'an to be applied in Indonesia. The research method that used by the writter is analysist description with library research, this research about Sayyid Quthb's thought which spreaded in many creation of writting that written became the book that written by someone or many other people. Ahlu Kitab depended on Sayyid Quthb are Jew and Christian generally, the meaning of that statement Sayyid Quthb didn't limit only for Israel scion (Ya'kub) but all of people who have ideologist as Jew and Christian ideologist, so that they are called Jew and Christian. Depended on Sayyid Quthb, Ahlu Kitab are infiedels politheist. Including people that have religion except Ahlu Kitab and the religions except Islam was still considered as infidel untill they believed in Muhammad and Al Qur'an. The research of this thesis is still about describing generally so that it still needs analysis deeply and in detail. In order to make new knowledge that can be guide for moslem in communication among them and not moslems.
\end{abstract}

Keywords: Ahlu Kitab, Sayyid Quthb, Tafsir fI zilal al-Qur'an.

Abstrak: Tujuan Allah SWT menciptakan manusia adalah untuk menyembah kepada-Nya. Kemudian Allah SWT menurunkan kitab suci al-Quran dan mengutus nabi-Nya sebagai penyampai kabar tentang peran Allah SWT dan Kitab yang hilang yang telah diturunkan kepada Muhammad SAW sebagai instruksi dan gambaran untuk orang-orang muslim sampai akhir zaman. Pertemuan antara Islam, Kristen, dan Yahudi telah berjalan sejak lahirnya Islam 
di Jazeera pad abad pertama Masehi, al-Qur'an merupakan kitab suci umat Islam berfungsi sebagai penyempurna kitab-kitab sebelumnya. Terutama kitab yang telah dibawa oleh orangorang Kristen (al-Kitab). Masalah Ahlu Kitab (Yahudi dan Kristen) sangat penting untuk dijelaskan, karena masalah ini berdampak pada aqidah dan berbagai aspek kehidupan umat Islam. Sayyid Qutb adalah seorang Mufassir di kalangan umat Islam, ia merupakan sosok yang sangat dicintai serta sebagai inspirator bagi umat Islam. Akan tetapi, di sisi lain, ia juga sering dikritik oleh para ulama lain, karena dianggap terlalu sulit dalam memahami tafsirtafsirnya. Setelah kematiannya, ideologi Sayyid Qutb tidak hilang dan menurun, di sisi lain ia lebih berkembang tidak hanya di Mesir tapi menyebar ke semua negara di dunia, akhirnya gerakan fundamentalis muncul. Sehingga penulis ingin menganalisis tentang Ahlu Kitab berdasarkan pada buku Sayyid Qutb, yang disebut Tafsir fi dilalil Qur'an untuk diterapkan di Indonesia. Metode penelitian yang digunakan adalah deskripsi analitik, jenis kepustakaan. Hasil penelitian adalah, bahwa Ahlu Kitab yang berpedoman pada Sayyid Quthb adalah orang Yahudi dan Kristen pada umumnya, artinya Sayyid Quthb tidak membatasi hanya untuk bani Israel (Ya'kub), tetapi semua orang yang memiliki ideologi Yahudi dan Kristen mereka dipanggil Yahudi dan Kristen. Berdasarkan pada Sayyid Quthb, Ahlu Kitab adalah anti politisi. Termasuk orang-orang yang beragama kecuali Ahlu Kitab dan agama-agama kecuali Islam masih dianggap sebagai kafir sampai mereka percaya kepada Muhammad dan al-Qur'an. Penelitian tesis ini masih membahas secara umum sehingga masih memerlukan analisis secara mendalam dan secara rinci. Untuk mendapatkan pengetahuan baru yang bisa menjadi panduan bagi umat Islam dalam berkomunikasi di antara mereka dan dan juga dengan umat non Islam.

Kata kunci: Ahlu Kitab, Sayyid Quthb, Tafsir fI zilal al-Qur'an.

\section{PENDAHULUAN}

Tujuan Allah menciptakan manusia adalah untuk beribadah kepada-Nya, dan meninggalkan ibadah kepada selain-Nya. Kewajiban ini juga dibebankan kepada golongan jin. Jadi, tugas pokok manusia dan jin hanya untuk beribadah kepada Allah semata. ${ }^{1}$ Sebagai pedoman dalam menjalakan ibadah di muka bumi ini, maka Allah mengutus nabi-nabi untuk membimbing manusia untuk beribadah dengan benar dan ikhlas. Tidak ada bercampur dengan kesyirikan sedikitpun. ${ }^{2}$ Kemudian bersama mereka Allah menurunkan kitab-kitab, dan suhuf sebagai pedoman yang harus disampaikan kepada umat mereka. Kitab yang bersumber dari Allah disebut Kitab Samawi, dan kitab yang bukan dari Allah disebut Kitab Ardi. ${ }^{3}$

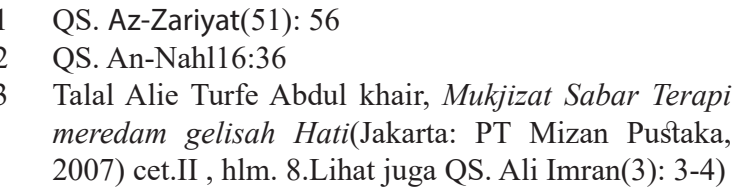

Al-Qur'an merupakan Kitab Samawi yang terakhir yang diturunkan Allah yang diturunkan kepada Nabi Muhammad sebagai petunjuk bagi manusia, pembeda antar hak dan batil, dan sebagai obat bagi manusia. Dan Al-Qur'an laksanan cahaya yang terang di siang hari, sabagai petunjuk bagi manusia hingga hari kiamat. ${ }^{4}$

Dalam memahami Al-Qur'an diperlukan disiplin ilmu tersendiri, dalam Islam tidak semua orang berhak menafsirkan Al-Qur'an, kecuali telah terpenuhi kriteria sebagai seorang mufassir. Bahkan Rasulullah mengancam orangorang yang menafsirkan Al-Qur'an dengan

4 QS. Al Maidah(5): 15-16 yang artinya: "Hai ahli kitab, Sesungguhnya Telah datang kepadamu Rasul kami, menjelaskan kepadamu banyak dari isi Al Kitab yang kamu sembunyi kan, dan banyak (pula yang) dibiarkannya. Sesungguhnya Telah datang kepadamu cahaya dari Allah, dan Kitab yang menerangkan. Dengan Kitab Itulah Allah menunjuki orang-orang yang mengikuti keredhaan-Nya ke jalan keselamatan, dan (dengan Kitab itu pula) Allah mengeluarkan orang-orang itu dari gelap gulita kepada cahaya yang terang benderang dengan seizin-Nya, dan menunjuki mereka ke jalan yang lurus". 
mengedepankan akal mereka. Orang-orang tersebut akan dimasukkan ke neraka. ${ }^{5}$

Perjumpaan Islam, Kristen(Nasrani) dan Yahudi sudah berlangsung sejak kelahiran agama Islam di jazirah Arabia pada awal abad ke tujuh Masehi. Dalam perjumpaan itu, Al-Qur'an yang merupakan kitab suci umat Isam memposisikan dirinya sebagai musaddiq (pembenar) dan muhaimin (Pemberi koreksi) terhadap kitab zuci sebelumnya ${ }^{6}$ utamanya kitab yang dipegang oleh kaum Kristen, ${ }^{7}$ yaitu yang dikenal Al Kitab. Posisi al-Qur'an yang demikian itu menjadikan perjumpaan itu bersifat ambivalen; satu sisi bersifat konflik dan sisi lain sebuan kritik terhadap doktrin Kristen (Nasrani), seperti Trinitas. Dua model hubungan inilah yang menjadikan hubungan keduanya menjadi fluktuatif; kadang bekerjasama dan kadang konflik. Walaupun penyebab konflik tidak sematamata disebabkan oleh agama, tapi kadang disebabkan faktor sosial. ${ }^{8}$

Yahudi dan Islam selalu menarik untuk diperbincangkan terutama dalam konteks pergualatan akademik. Menarik karena Yahudi bagi sebagian umat Islam, sudah mendapat stigma bahwa ia tidak akan mengakui eksistensi agama Islam selama umat Islam tidak mengikuti agama mereka. ${ }^{9}$ Ditambah lagi adanya konflik antara Israel dan penduduk Palestina yang belum berhenti, walaupun korban semakin

5 Ibnu Katsir, Terjemah Singkat Tafsir Ibnu Katsir JIlid 1, (Surabaya: PT Bina ilmu, 2005) hlm. xvii

6 Lihat QS. Al-Maidah/5: 48

7 Kata kristen berasal dari kata kristus, gelar kehormatan bagi Yesus dari Nazareth kristus bersalal dari bahasa Yunani(khristos) yang berarti yang dirupai. Selain itu, agama ini dinamakan juga Masehi, yang artinya sama dengan yang berasal dari bahasa Yunani .Nama ini sama dengan yang diberikan $\mathrm{Al}$ Qur'an terhadap pembawa agama ini, yaitu Al-Masih 'Isa bin Maryam. Lihat QS. Ali Imran/3: 45, An-Nisa/4: 157, 72, 75. Berdasarkan ini, pengikut agama tersebut disebut denagn an Nashara. Lihat QS. Al Baqarah/2: 72, 111, 113, 120, 135, 140. Maka, Agama Kristen disebut juga Agama Nasrani.

8 Waryono, Beberapa problem teologi, (Yogyakarta: UIN Jogyakarta,Jurnal Esensia Vol. XII, terbit 1 Januari 2012) hlm. 97-98.

9 Lihat QS. Al-Baqarah/2: 120 ini dijadikan senjata pamungkas untuk menyerang Yahudi. bertambah baik dari penduduk Palestina maupun Israel.

Dalam Al-Qur'an, kata Ahlu Kitab ditemukan sangat banyak. Menurut Syaikh Muhammad Abdul Al Baqi' dalam kitab AlMu'jam Al-Mufahras li alfaz Al-Qur'anil Karim, kata Ahlu Kitab disebutkan secara langsung di dalam sebanyak 31 kali dan tersebar pada 9 surat yang berbeda. Kesembilan surat tersebut adalah Al-Baqarah, Ali 'Imran, Al-Nisa', Al-Maidah, Al-Ankabut, Al-Ahzab, Al-Hadid, Al-Hasyr, dan AzlBayyinah. ${ }^{10}$ Dari kesembilan surat tersebut hanya al-Ankabut-lah satu-satunya ayat yang termasuk dalam surat Makkiyah dan selebihnya termasuk dalam suratsurat Madaniyah. Dengan demikian dapat diketahui bahwa interaksi umat Islam dengan Ahlu Kitab sudah dimulai dari di Makah, hanya saja intensitasnya tidak terlalu banyak sebagaimana di Madinah.

Berbagai persoalan mengenai Ahlu Kitab (Yahudi dan Nasrani) ini sangat penting dikemukakan karena permasalahan ini berimbas pada masalah akidah, ibadah, muamalah dan berbagai aspek kehidupan bagi kaum muslimin. Dan siapakah Ahlu Kitab ini pun masih diperselisihan Para Ulama, terutama makna Ahlu Kitab pada masa sekarang ini, apakah termasuk Ahlu Kitab atau tidak agama Hindu, Buda, Konghucu? Hal-hal di berikut yang menuntut adanya penelitian tentang siapakah yang dimaksud Ahlu Kitab.

Perbedaan ulama dalam mensikapi Ahlu Kitab belum sepakat dalam berbagai hukum dalam syariat Islam; perselisiahan ulama adalah dalam masalah pernikahan seorang muslim dengan wanita Ahlu Kitab, atau pernikahan wanita muslimah dengan laki-laki Ahlu Kitab, kehalalan hewan sembelihan Ahlu Kitab, dan berdoa untuk mereka.

Melihat berbagai perbedaan ulama dan memaknai Alhu Kitab dan dalam hukum yang berhubungan dengan Ahlu Kitab,

10 Gus Arifin, Menikah Untuk Bahagia Dan Kamasutra Islami, (Jakarta: PT Alex Media Komputindo Kompas Gramedia, 2010) hlm. 156 
maka pembahasan tentang Al-Qur'an, terutama dalam permasalahan Ahlu Kitab tidak akan pernah lekang oleh zaman, dan pembahasan tema Al-Qur'an ini sebagai sarana untuk tas \abbut (rekonfirmasi) tentang pemikiran Al-Qur'an yang menjadi pedoman hidup umat Islam hingga hari kiamat. ${ }^{11}$

Sayyid Quthb adalah salah seorang mufasir yang kontroversi di kalangan umat Islam. Bagi kalangan Ikhwanul Muslimin(IM), Sayyid Quthb merupakan tokoh yang sangat disegani dan menjadi inspirator bagi orang-orang yang ada di dalamnya. Tetapi, di sisi lain, pemikiran Sayyid Quthb dikritisi oleh ulama dikarenakan kerancuan dalam berpikir, menafsirkan ayat-ayat Al-Qur'an dan beberapa penyelewengan akidahnya, terutama dalam masalah takfir ${ }^{12}$ terhadap orang-orang yang tidak sefaham dengannya $^{13}$ Walaupun Sayyid Quthb memiliki kerancuan bepikir dalam masalah takfir, Pemikiran-pemikiran politiknya ${ }^{14}$ telah memberikan perngaruh pada gerakangerakan pemuda dalam menghadang Barat di berbagai Negara terutama Mesir. Secara tidak langsung, teori Quthb yang mengakibatkan lahirnya golongan pejuang muslim dengan teori politik Quthb yang mengakibatkan lahirnya golongan pejuang muslim garis keras di beberapa belahan bumi. ${ }^{15}$

Sepeninggal Sayyid Quthb, ideologis Sayyid Quthb bukan hilang dan berkurang,

11 M. Idris. A. Shomad, M.A, Al Qur'an Sebagai Wahyu Ilahi, (Jakarta: Jurnal Al Insan, 2005) hlm. 78.

12 Takfir artinya kaidah mengkafirkan orang lain. Kaidah dalam permasalalah takfir ini harus dikembaalikan pada Al-Qur'an dan Sunah. Karena tidak semaua dikatakan kufur karena perubatannya atau perkataanya dan mengeluarkan ia dari agma Islam. hlm. 2

13 Muhammad As Sewwed, Bahaya Pemikiran Sayyid Quthb,(Online), http://www.darussalaf.or.id/ hizbiyyahaliran/bahaya-pemikiran-sayyid-quthb/, diakses 4 November 2014

14 Rumusan masalah politik dan pekiran Sayyid Quthb dalam masalah politik telah ditulis dalam kitab Ma'alim fi At-Tariq.

15 Juandi, Pemikiran Politik Sayyid Quthb Melacak Geneologi “Kekerasan",makalah diakses dari internet pada tanggal 26 November 2015 sebaliknya semakin berkembang bukan hanyadiMesirsaja tapimenyebarkeberbagai Negara di dunia. Akhirnya, munculah gerakan-gerakan fundamentalis ${ }^{16}$. Adapun gerakan yang dianggap fundamentalis di Indonesia yang di terpengaruh pemikiran Sayyid Quthb adalah Dewan Dakwah Islamiah Indonesia, Majelis Mujahidin Indonesia (MMI) Front Pembela Islam (FPI), Laskar Jihad, dan seterunya. ${ }^{17}$

Sebagai manusia biasa, Sayyid Quthb tidak pernah lepas dari salah, termasuk Tafsir Fi Zilal Al-Qur'an. Syaikh Saleh bin Abdil Aziz Alu Syaikh berkata, bahwa Quthb termasuk orang yang gulat (ektrim) ${ }^{18}$ dalam masalah agama, sehingga ia mudah mengkafirkan atau memasukkan orang yang mentaati manusia dalam hal yang haramkan oleh Allah, dihukumi sebagai orang musyrik atau menyekutukan Allah yang menyebabkan pelakukan keluar dari Islam, karena berhukum dengan hukum selaian Allah ${ }^{19}$

Dari pemaparan di atas diketahui bahwa Sayyid Quthb mewariskan "sikap keras" kepada umat Islam ini, tetapi dengannya Ia disanjung di kalangan pendukungnya.

16 Fundamentalisme adalah sebuah gerakan dalam sebuah aliran, paham atau agama yang berupaya untuk kembali kepada apa yang diyakini sebagai dasar-dasar atau asas-asas (fondasi). Karenanya, kelompok-kelompok yang mengikuti paham ini seringkali berbenturan dengan kelompok-kelompok lain bahkan yang ada di lingkungan agamanya sendiri. Mereka menganggap diri sendiri lebih murni dan dengan demikian juga lebih benar daripada lawan-lawan mereka yang iman atau ajaran agamanya telah "tercemar".Kelompok fundamentalis mengajak seluruh masyarakat luas agar taat terhadap teks-teks Kitab Suci yang otentik dan tanpa kesalahan. Mereka juga mencoba meraih kekuasaan politik demi mendesakkan kejayaan kembali ke tradisi mereka. Lihat di http://id.wikipedia. org/wiki/Fundamentalisme, diakses 6 November 2014

17 Abd A'la, Sikap Muslim FundamentalisIndonesia Terhadap NKRI Antara Penolakan dan Penerimaan Setengah Hati, Jurnal UNISIA, Vol. 33, No. 73 Juli 2010: 59

18 Gulat berasal dari kata gala-yaglu, guluwan yang artinya berlebih-lebihan atau melampaui batas ukuran. Dalam agama Islam guluw merupakan hal yang terlarang. Lihat Yazid bin Abdul Qadir Jawwas, Syarh 'Aqidah Ahlus Sunnah wal Jama'ah,(Bogor: Pustaka Imam Syafi'i, 2006). hIm 268

19 Isham As-Sina'i, Fatwa-Fatwa Ulama Tentang Sayyid Quthb, (-------, Makbatab Abu Salma Al Atsari: 2007) hlm. 36 
Tetapi, di sisi lain kritikan ulama-ulama juga sangat keras terhadapnya. Lantas bagaimanakan konsep Sayyid Quthb tentang Ahlu Kitab dalam Kitab Tafsir Fi Zilal Al-Qur'an? dan bagaimanakah cara berininteraksi dengan mereka.

Dengan latar belakang di atas, maka penelitian tentang konsep Sayyid Quthb mengenai Ahlu Kitab ini sangat penting. Karena dapat menjadi wacana bagi kalangan akademisi dan sebagai keterangan (taujih) bagi masyarakat muslimin pada umumnya.

\section{Landasan Teori}

Ibnu Katsir dalam tafsir Tafsiru AlQur'ani Al-Azim menjelaskan bahwa Ahlu Kitab adalah orang-orang Yahudi dan Nasrani dimanapun mereka berada tidak terbatas hanya Yahudi dan Nasrani keturunan Bani Israil. ${ }^{20} \mathrm{Hal}$ ini disampaikan ketika menafsirkan QS. Al Maidah ayat 5:

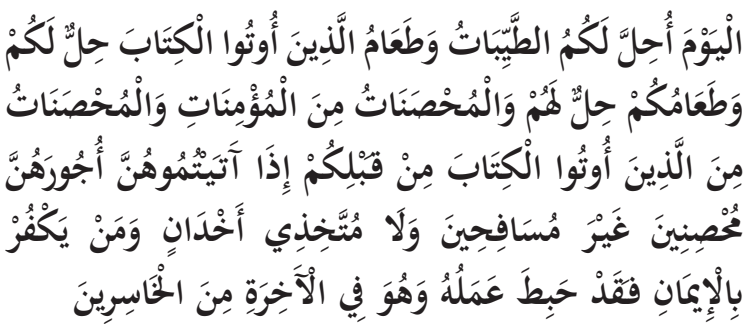

Pada hari Ini dihalalkan bagimu yang baikbaik. makanan (sembelihan) orang-orang yang diberi Al Kitab itu halal bagimu, dan makanan kamu halal (pula) bagi mereka. (dan dihalalkan mangawini) wanita yang menjaga kehormatan diantara wanitawanita yang beriman dan wanita-wanita yang menjaga kehormatan di antara orangorang yang diberi Al Kitab sebelum kamu, bila kamu Telah membayar mas kawin mereka dengan maksud menikahinya, tidak dengan maksud berzina dan tidak (pula) menjadikannya gundik-gundik. barangsiapa yang kafir sesudah beriman (Tidak menerima hukum-hukum Islam) Maka hapuslah amalannya dan ia di hari kiamat termasuk orang-orang merugi. ${ }^{21}$

20 Ibnu Katsir, ami'ul Bayan Fi Ta'wili Al-, Maktabah syamilah, hlm 107

21 QS. Al Maidah:5
Pendapat serupa juga disamapaikan oleh As Sa'di, 22 Tim Pengajar Tafsir('adadu asatizah at-tafsir) di bawah bimbinga Abdullah At Turki, hanya saja dalam Tafsir Al-Muyassar ditambahkan bahwa Ahlu Kitab bukan hanya mereka yang menerima kitab dari Allah, tetapi adalah semua orang dan setiap masa yang mana mereka memeliki keyakinan sama seperti mereka atau orang yang masuk agama mereka. ${ }^{23}$

Hal yang masih menjadi perdebatan ulama hingga sekarang ini adalah permasalahan Sembelihan Ahlu Kitab. Menurut syaikh As-Sa'di berkata bahwa sembelihan Ahlu Kitab Yahudi dan Nasrani halal bagi kaum muslimin, namun tidak demikian dengan orang kafir selain Yahudi dan Nasrani. Para rasul semuanya telah sepakat atas haramnya sembelihan yang dipersembahkan untuk selain Allah, karena ini termasuk perbuatan syirik. Sedangkan agama Yahudi dan Nasrani sampai sekarang masih mengharamkan sembelihan yang dipersembahkan untuk selain Allah. ${ }^{24}$ Tetapi, jika sembelihan Ahlu Kitab ditujukan kepada selain Allah, maka hukum memakan sembelihan tersebut tetap haram..$^{25}$

Selain sembelihan Ahlu Kitab, pernikahan dengan mereka merupakan permasalahan yang masih diperdeabatkan oleh para ulama. Kebanyakan ulama mengatakan bahwa diperbolehkan lakilaki mukmin menikahi wanita Ahlu Kitab dengan alasan wanita Ahlu Kitab tersebut adalah wanita baik-baik, merdeka dan menjaga kehormatannya, bukan pelacur. ${ }^{26}$

Sedangkan ulama Madzab Hanafi memberikan syarat diperbolehkan

22 As Sa'di, Taisi $>$ rul Kari $>$ mir Rohmah fi $>$ Tafsiril Kala $>$ m Ar-Rahma $>h$, (Muasaasah Ar-risalah, 2002) hlm 121

23 Tim Asatiz Tafsir, At Tafsir Al Muyassar, Maktabah Syamilah. Juz II hlm. 179

24 As-Sa'di, Taisi $>$ rul Kari>mir Rohmah fi> Tafsiril Kala $>$ m Ar-Rahma $>$ h, (Muasaasah Ar-risalah, 2002) hlm 221

25 Ibid, hlm 219

26 Abu Ubaidah Usamah bin M. Jamal, Shahih Fiqih Wanita: Kajian Terlengkap Fiqih Wanita Berdasarkan AL QUr'an dan Hadits-Hadits Shahih,(Solo:Insan Kamil Cet-IV, 2013) hlm.250 
pernikahan antara laki-laki muslim dan wanita Ahlu Kitab adalah ditempat yang aman, bukan kondisi perang, karena ditakutkannya anak-anaknya akan mengikuti agama ibunya. ${ }^{27}$

Walaupun laki-laki muslim diperbolehkan menikahi wanita Ahlu Kitab, tetapi hukum ini tidak berlaku sebaliknya, yaitu laki-laki Ahlu Kitab tidak boleh menikahi wanita muslimah. ${ }^{28}$ Karena hukumnya haram dan tidak sah.

\section{METODE PENELITIAN}

Sebagai sebuat studi, penelitian ini dari sisi pengumpulan data bersifat riset perpustakaan (library research). Kajian ini meneliti tentang pemikiran Sayyid Quthb yang tersebar diberbagai tulisan yang ditulis oleh dalam bentuk buku dan artikel baik yang ditulis sendiri maupun yang kumpulkan orang lain.

Karenanya itu kajian ini menggunakan dua jenis sumber data, yaitu sumber data primer dan sumber data sekunder. Data primer -rujukan utama- dan sekaligus fokus obyek kajian dalam penelitian ini- adalah Tafsir Fi Zilali Al-Qur'an karya Sayyid Quthb, sedangkan data sekunder adalah data-data yang bisa dijadikan bahan penunjang dalam pembahasan, baik yang berupa buku, artikel, dan jurnal.

Dalam penelitian ini digunakan dua pendekatan, yaitu pendekatan pendekatan filosofis. Pendekatan filosifis digunakakan untuk mengungkap pemikiran Sayyid Quthb tentang Ahlu Kitab, hal-hal yang mempengaruhi pendapat tersebut, dan implementasinya dalam kehidupan di Indonesia.

Teknik pengumpulan data dalam penelitian ini adalah mengunpulkan dokumentasi yang ditemukan di perpustakaan baik dalam bentuk buku, majalah, artikel, jurnal dll. Setelah data

27 Suhadi, Kawin Lintas Agama:Persepektif Nalar Islam, (Yogyakarta: LKis, 2006) hlm 40

28 Abu Ubaidah Usamah bin M. Jamal, Shahih Fiqih Wanita: Kajian Terlengkap Fiqih Wanita Berdasarkan AL QUr'an dan Hadits-Hadits Shahih,(Solo:Insan Kamil Cet-IV, 2013) hlm.250 terkumpul akan kita uji validitas dengan teknikuji transferability, kemudian dianalisis dengan menggunakan analisis enterpretatifkomparatif $f^{29}$.

\section{HASIL DAN PEMBAHASAN}

\section{Ahlu Kitab bermakna Yahudi dan Nasrani}

Ahlu Kitab menurut Sayyid Quthb adalah Yahudi dan Nasrani. Tetapi, tida semua ungkapan Ahlu Kitab bermakna secara langsung kepada Yahudi dan Nasrani secara bersamaan ${ }^{30}$, karena term Ahlu Kitab bermakna Yahudi saja, ${ }^{31}$ Nasrani saja ${ }^{32}$. Hal ini sangat Nampak, ketika menjelaskan ayat-ayat tentang Ahlu Kitab bahwa makna Ahlu Kitab adalah Yahudi dan Nasrani. Tetapi, Dalam penjabarannya, Quthb tidak memabatasi makna Ahlu Kitab terbatas hanya Yahudi dan Nasrani yang merupakan keturunan Bani Israel, tetapi lebih luas dari itu, bahwa semua orang yang meyakini kitab-kitab yang diturunkan Allah, baik Taurat maupun Injil, walaupun ia bukan keturunan Yahudi tetap disebut Ahlu Kitab.

Penafsiran Ahlu Kitab menurut Sayyid Quthb ini seleras dengan pendapat Syaikh As-Sa'di, ${ }^{33}$ At-Tabarai ${ }^{34}$, Ibnu Katsir ${ }^{35}$, dan Al-Bagawi. Penafsiran ini nampak sekali ketika menafsirkan QS. Al-Bayyinah ayat 1. Hanya saja, dalam menjabarkan makna Ahlu Kitab, Sayyid Quthb menjelaskan

29 Metode Komparatif ialah: (1) membandingkan teks ayat-ayat Al Qur'an yang memiliki persamaan atau kemiripan redaksi dalam dua kasus atau lebih dan atau memiliki redaksi yang berbeda dalam kasus yang sama;(2) membandingkan pendapat ulama tafsir dalam menafsirkan Al Qur'an. Lihat Nashruddin Baidah, Metodologi Penafsiran Al Qur'an,(Yogyakarta: Pustaka Pelajara, 1998) hlm.65

30 Lihat. QS Al Ali Imran: 64 dan 65, Ali Imran QS. 6465, 69-72, 75

31 Lihat QS. Al Baqarah: 105 dan 109

32 Lihat QS. An Nisa/4: 171 dan Al Maidah/5: 77

33 Abdurrahman bin Nasir bin As-Sa'di, Taisi $>$ rul kari $>m i$ ar-rahmah fi> tafsi $>$ ril kala $>$ mil manna $>$ n,(Bairut:Muassasah Ar-Risalah, 2000) hlm. 931

34 Abu Ja'far At-Tabari, Jami ' $u \quad A l-$ Baya $>n$ fi $>$ Takwi>li Al-Qur'an, (__ : Al-Muassasah ArRisalah, 2000) juz XXIV, hlm.539

35 Ibnu Katsir, Tafsi $>r$ Al-Qur'ani Al-Az\}i>m. ( : Daru Tiba'ah li an-Nasr wa at-tauzi', 1999) juz VIII. hlm. 456 
dengan pendekatan sejarah yang mana makna Ahlu Kitab yang dimaksud Yahudi dan Nasrani yang berada di Madinah, atau yang berinteraksi dengan Nabi Muhmmad. Tetapi, Sayyid Quthb dalam menjelaskan makna Ahlu Kitab ini tidak membatasi makna Ahlu Kitab itu hanya dari keturunan Bani Isranil saja.

Karenanya, dapat disimpulkan bahwa dalam menjelaskan makna Ahlu Kitab, Sayyid Quthb tidak tidak menyelisihi ulama-ulama salaf, dan para mufasir terdahulu. Hanya saja, Dalam menafsirkan ayat-ayat Ahlu Kitab pada khususnya, dan dalam menafsirkan ayat-ayat dalam Al-Qur'an, Sayyid Quthb menggunakan gaya bahasa bercerita yang mengalir, enak dibaca dan mudah difahami oleh orang yang berpendidikan maupuan yang tidak, serta dapat emosi seseorang sesuai dengan apa yang diinginkannya.

Tetapi, jika diperhatikan dalam metode penyajian dan gaya penafsiran Al Qur'an, Sayyid Quthb akan didapatkan bahwa metode yang digunakan berbeda dengan metode yang digunakan oleh ahlu tafsirahlu tafsir yang lain, seperti Ibnu Katsir, Imam At\}-T\{abari, Abu Bakar Al-Jazairi, dan lain-lain. Karena dalam menafsirkan ayat-ayat dalam Al Qur'an, Quthb sangat jarang mencantumkan hadis-hadis dan atsar-atsar dari para sahabat dan ulama. Kekurangan dalam penyajian inilah yang menjadikan bahan kritian oleh ulamaulama, diantaranya adalah Syaikh Abdul Muhsin Abbad, ia menjelaskan bahwa dalam tulisan Quthb tidak akan didapatkan tulisan, "Fulan berkata, Fulan mengatakan, Rasulullah bersabda demikian dan demikian ....". dan seterusnya. Hal ini disebabkan penulisan tafsirnya Sayyid Quthb tidak dibangun di atas atsar, tetap dibangun di atas pendapat dengan fikiran, oleh sebab itulah ia banyak mengungkapkan pendapat yang tidak shahih. ${ }^{36}$

36 Abu Salma Al Atsari, , Fatwa-fatwa Ulama Umat Tentang Sayyiqd Quthb, diterjemahkan oleh Abu Salma Al Atsari, (--------: Maktabah Abu Salma, 2007) hlm.31-32
Syaikh 'Abdul Muhsin Al-'Abbad melanjutkan bahwa tulisan Sayyid Quthb pada tafsir sangat minim mengangkat hadits-hadits dan atsar-atsar dari ulama dikarenaka Sayyid Quthb bukanlah seorang yang alim, tetapi di adalah seorang sastrawan yang memiliki kemapuan menulis dan mengarang serta berkata-kata dengannya, sehingga muncul dari perkataannya itu suatu yang benar dan yang salah. ${ }^{37}$

\section{Kekafiran Ahlu Kitab dan Agama Selain Islam}

Menurut Sayyid Quthb, agama di luar agama Islam adalah kafir, tidak diterima keimanan mereka, termasuk Ahlu Kitab. Ahlu Kitab ini dimasukkan ke dalam golongan kafir oleh Sayyid Quthb dengan alasan seabgai berikut:

a. Meraka tidak beragama dengan agama yang benar

Orang-orang Yahudi mengatakan bahwa mereka golongan yang mendapat keistimewaan dari Allah, bahwak mereka mengatakan bahwa "kami adalah anak-anak Allah"38, diutus kepada mereka Nabi Musa yang membawa Taurat sebagai undangundang dalam kehidupan mereka. Tetapi dalam kehidupan beragama mereka jauh dari akhlak-akhlah orang yang beragama. Mereka menyelisihi perintah nabi-nabi yang diutus Allah kepada mereka, bahkan ada yang mereka bunuh dikarenakan tidak sama dengan apa yang diinginkan oleh hawa nafsu mereka.

Pendapat Sayyid Quthb tentang kekafiran Ahlu Kitab yang dibsebabkan mengatakan Allah merupakan sau dari tiga oknum meruapakan pendapat yang selaras dengan para mufassirmufassir yang lain seperti Ibnu Katsir, Muhammad bin Ali As-Syaukani, ${ }^{39}$ dan syaikh As-Sa'di.

$37 \quad$ Ibid., hlm.32

38 Lihat QS. AL Maidah/5: 18

39 Muhammad bin Ali As-Syaukani, Fathu Al-Qadi $>$, (Libanon: Darul Ma'rifah, 1428H/2007). hlm. 567 
b. Mereka menyembah rahib-rahib mereka

Kata "Menenyembah rahibrahib mereka" artinya adalah mereka menghalalkan apa yang dihalalkan dan mengharamkan apa yang diharamkan oleh rahib-rahib mereka, walaupun apa yang diucapkan rahib-rahib tersebut bertentangan dengan kitab-kitab mereka (Taurat dan Injil).

Ketaatan kepada rahirahib(pendeta-pendeta) yang dilakukan oleh Ahlu Kitab menjadikan mereka melakukan kesyirikan dan kekafiran. Ketaatan yang seperti ini yang disebut dengan al-muttahizina lahum arbaban min dunillah. ${ }^{40}$ Adapun keyakinankeyakina yang diyakini oleh orangorang Yahudi nan Nasrani itu muncul kecuali dikarenakan menaati hawa nafsu mereka. ${ }^{41}$

3. Mereka memerangi agama Allah

Ahlu Kitab(Yahudi dan Nasrani) tidak akan berhenti memusuhi kaum muslimin hingga kaum musilimin mengikuti agama (milah) mereka. Selama umat Islam masih konsisten dengan ajaran agama Islam, maka mereka akan senantiasa memeranginya hingga hari kiamat.

Tujuan dari Ahlu Kitab memerangi kaum muslimin adalah agar cahaya Allah (nur Allah) dari muka bumi menjadi padam. Tapi Allah menjaga umat Islam dan cahanya-Nya dari pemadaman Ahlu Kitab, bahkan Allah menyempurnakannya sehingga nampak jelas cahaya Allah di muka bumi ini. Untuk mensukseskan program mereka untuk menguasai dunia, maka Ahlu Kitab membuat jaringan internasional yang dikenal dengan zionisme internasional dan salibis internasional, bahkan kadangkadang mereka bekerjasama dengan komunisme internasional. hal ini senantiasa dilakukan oleh orang-orang Yahudi hingga

$40 \quad$ Ibid., hlm. 567

41 Abdurrahmah As-Sa'di, Tafsir Al-Kari $>m$ ArRahma $>n$ fi Tafsi $>$ ri Kala $>$ m Al-Manna $>$ n, (Bairut, Muassasah Ar-Risalah), hlm. 335 akhir kiamat.

\section{Ahlu Kitab Mengubah kitab-kitab yang Diturunkan Allah Kepada Mereka Sesuai dengan Hawa Nafsu Mereka.}

Adapun agama selain Islam, menurut Sayyid Quthb merupakan orang kafir yang jelas. Karena mereka tidak beriman dan melaksanakan apa yang ada dalam kitab mereka, itu pun berlaku sebelum diutusnya Nabi Muhammad. Adapun setelah diutusnya Rasulullah tidak akan diterima keimanan tersebut, kecuali dengan beriman kepada Nabi Muhammad dan Al-Qur'an.

Dari penjelasan di atas dapat diketahui bahwa Ahlu Kitab menurut Sayyid Quthb adalah Kafir dan musyrik. Kekafiran Ahlu Kitab ternyata juga dinyatakan oleh ulama dan Ahlu tafsir seperti Syaikh Utsaimin, ${ }^{42}$ Ibnu Katsir ${ }^{43}$, At-Thabari, ${ }^{44}$ Al-Bagawi ${ }^{45}$, dan As-Sa'di ${ }^{46}$

\section{KESIMPULAN}

Setelah melakukan penelitian tentang konsep Sayyid Quthb dalam Tafsir fi zilal Al-Qur'an, dapat dikemukakan beberapa kesimpulan sebagai berikut: 1). Ahlu Kitab menurus Sayyid Quthb adalah Yahudi dan Nasrani secara umum, artinya Quthb tidak membatasi hanya keturunan Israil(Nabi Ya'qub) saja, tetapi semua orang yang berideologi seperti Yahudi dan Nasrani, maka mereka disebut juga Yahudi dan Nasrani. Pendapat ini sama dengan pendapat Imam Abu Hanifah dan Mazhab Abu Hanifah, Penafsiran Ahlu Kitab menurut Sayyid Quthb ini seleras dengan

42 Muhammad bin Shalih Al-Utsaimin, Majmu' Fatawa wa Ar-Rasa'il,(Riyadh: Darul Wathan li an-Nashr, 1413H) hlm. 18-23

43 Ibnu Katsir, Tafsi $>r$ Al-Qur'ani Al-Az\}i>m.(: Daru Tiba'ah li an-Nasr wa at-tauzi', 1999) juz III. hlm. 157

44 Abu Ja'far At-Tabari, Jami>'u Al-Baya>n fi> Takwi>li Al-Qur'an, (__ : Al-Muassasah ArRisalah, 2000) juz X, hlm 481

45 Al-Bagawi, Ma'alim At-Tanzil, (.) _ _ : Daru Tiba'ah li an-Nasr wa at-tauzi', 1997) juz III, hlm.32

46 Abdurrahman bin Nasir bin As-Sa'di, Taisirul karimi ar rahmah fi tafsiril kalamil mannan,(Bairut:Muassasah Ar-Risalah, 2000) hlm. 239 
pendapat Syaikh As-Sa'di, ${ }^{47}$ At-Tabari ${ }^{48}$, Ibnu Katsir ${ }^{49}$, Al-Bagawi, dan Muhammad Qurays Shihab. 2). Ahlu Kitab dimasukkan oleh Sayyid Quthb ke dalam golongan orang-orang kafir dan musyrik, termasuk juga orang-orang yang menganut agama selain Yahudi dan Nasrani: seperti Hindu, Budha, Konghucu, Sinto dan lain-lain. 3). Kekafiran Ahlu Kitab disebabkan beberapa hal: pertama, mereka tidak beragama dengan agama yang benar. Hal ini disebabkan tata cara beragama mereka tidak sesuai dengan apa yang diajarkan dalam kitab suci mereka. Kedua, mereka menyembah rahibrahib mereka. Makna menyembah rahibrahib mereka yaitu mereka mentaati semua hal-hal yang diucapkan oleh rahib-rahib mereka, walau ucapan mereka itu tidak bertentangan dengan isi kitab suci mereka. Ketiga, Ahlu Kitab senantiasa memerangi agama Allah. Keempat, Ahlu Kitab mengubah kitab-kitab yang diturunkan Allah kepada mereka sesuai dengan hawa

47 Abdurrahman bin Nasir bin As-Sa'di, Taisi $>$ rul kari $>m i$ ar-rahmah $f i>$ tafsi $>$ ril kala $>$ mil manna $>n$, (Bairut:Muassasah Ar-Risalah, 2000) hlm. 931

48 Abu Ja'far At-Tabari, Jami>'u Al-Baya>n fi> Takwi>li Al-Qur'an, ( : Al-Muassasah ArRisalah, 2000) juz XXIV, hlm.539

49 Ibnu Katsir, Tafsi $>r$ Al-Qur'ani Al-Az\}i>m. ( Daru Tiba'ah li an-Nasr wa at-tauzi', 1999) juz VIII, hlm. 456

agama selain Islam dimasukkan ke dalam golongan orang-orang kafir. Keimanan mereka tidak diterima setelah diutusnya Nabi Muhammad, kecuali dengan beriman kepada Nabi Muhammad dan Al-Qur'an. 5). Relevansi dari Sayyid Quthb terhadap makna Ahlu Kitab adalah sebagai berikut: a). Diperbolehkan berdoa untuk orang kafir yang maish hidup agar mereka mendapatkan hidayah dan kebaikan dunia, tetapi doa agar mereka diberi ampunan oleh Allah merupakan perbuatan yang dilarang dalam agama Islam, b). Diperbolehkan toleransi antara umat beragama, tetapi dalam masalah muamalah, bukan daam masaah ibadah dan akidah, c). Sembelihan Ahlu Kitab halal hukumnya jika diketahui mengucapkan nama Allah, tetapi jika diketahui tidak menyebut nama Allah, maka hukumnya haram untuk dimakan, d). Wanita muslim diharamkan untuk menikah dengan laki-laki non-muslim. Sedangkan laki-laki muslim dengan wanita Ahlu Kitab menurut ulama dibagi menjadi tiga, yaitu: 1). Jumhur ulama membolehkan; 2). Mengharamkan karena keumuman dalil dari QS. AL Maidah ayat 5; 3). Halal menikahi wanita Ahlu Kitab, tapi Karena unsur politik maka hukumnya menjadi dilarang.

\section{DAFTAR PUSTAKA}

Abd A'la, Sikap Muslim FundamentalisIndonesia Terhadap NKRI Antara Penolakan dan 
Penerimaan Setengah Hati, Jurnal UNISIA, Vol. 33, No. 73 Juli 2010: 59

Abdul khair, Talal Alie Turfe. 2007. Mukjizat Sabar Terapi meredam gelisah Hati. Jakarta: PT Mizan Pustaka,

Al Atsari, Abu Salma. 2007. Fatwa-fatwa Ulama Umat Tentang Sayyiqd Quthb, diterjemahkan oleh Abu Salma Al Atsari, (-------: Maktabah Abu Salma.

Al-Bagawi. 1997. Ma'alim At-Tanzil,. : Daru Tiba'ah li an-Nasr wa at-tauzi'.

Al-Utsaimin, Muhammad bin Shalih . 1413H. Majmu' Fatawa> wa Ar-Rasa>'il. Riyadh: Darul Wathan li an-Nashr.

As Sewwed, Muhammad. Bahaya Pemikiran Sayyid Quthb,(Online), http://www.darussalaf. or.id/hizbiyyahaliran/bahaya-pemikiran-sayyid-quthb/, diakses 4 November 2014

As-Sa'di, Abdurrahman bin Nasir . 2000. Taisirul karimi ar rahmah fi tafsiril kalamil mannan. Bairut:Muassasah Ar-Risalah.

As-Syaukani, Muhammad bin Ali. 2007. Fathu Al-Qadi>r, (Libanon: Darul Ma'rifah.

At-Tabari, Abu Ja'far . 2000. Jami>'u Al-Baya>n fi> Takwi>li Al-Qur'a>n,( : AlMuassasah Ar-Risalah

At-Tabari, Abu Ja'far . 2000. Jami'u Al-Baya>n fi Takwi li Al-Qur'a>n. : Al-Muassasah Ar-Risalah.

Gus Arifi .2010., Menikah Untuk Bahagia Dan Kamasutra Islami. Jakarta: PT Alex Media Komputindo Kompas Gramedia.

Ibnu Katsir. 1999. Tafsi>r Al-Qur'ani Al-Az\}i>m. : Daru Tiba'ah li an-Nasr wa at-tauzi'.

Isham As-Sina'i, Fatwa-Fatwa Ulama Tentang Sayyid Quthb, (-------, Makbatab Abu Salma Al Atsari: 2007) hlm. 36

Jawwas, Yazid bin Abdul Qadir. 2006., Syarh 'Aqidah Ahlus Sunnah wal Jama'ah. Bogor: Pustaka Imam Syafi'i

Juandi, Pemikiran Politik Sayyid Quthb Melacak Geneologi "Kekerasan",makalah diakses dari internet pada tanggal 26 November 2015

M. Idris. A. Shomad , 2005, Al Qur'an Sebagai Wahyu Ilahi. Jakarta: Jurnal Al Insan.

Suhadi. 2006. Kawin Lintas Agama:Persepektif Nalar Islam, (Yogyakarta: Lkis.

Tim Asatiz Tafsir, At Tafsir Al Muyassar, Maktabah Syamilah.

Usamah bin M. Jamal, Abu Ubaidah. 2013. Shahih Fiqih Wanita: Kajian Terlengkap Fiqih Wanita Berdasarkan AL QUr'an dan Hadits-Hadits Shahih. Solo:Insan Kamil.

Waryono. 2010. Beberapa problem teologi,. Yogyakarta: UIN Jogyakarta,Jurnal Esensia Vol. XII, terbit 1 Januari 2012. 